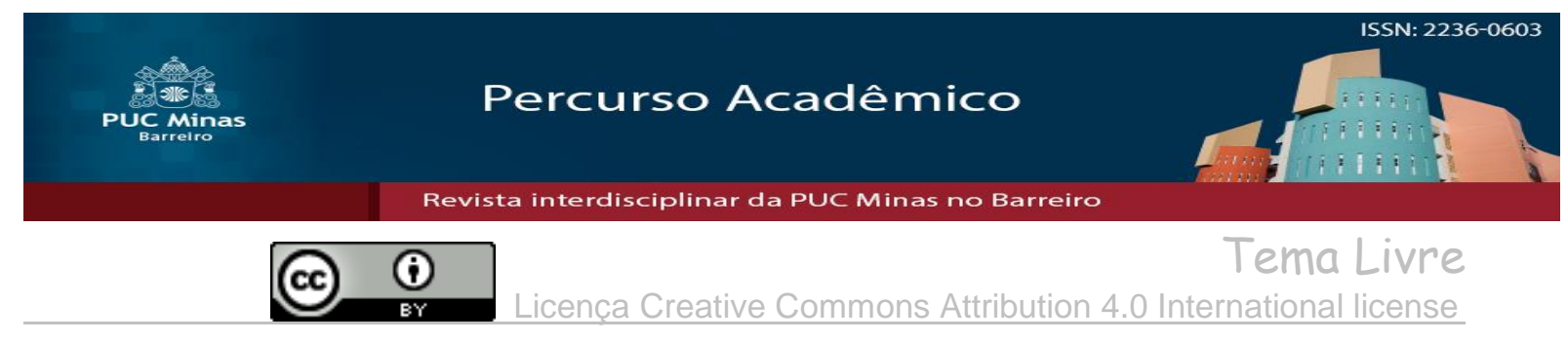

\title{
Percepção de profissionais e gestores sobre a promoção da saúde dos idosos institucionalizados
}

\section{Healthcare professionals and managers` perceptions on institutionalized older adults' health promotion}

\author{
Tatiana Resende Prado Rangel Oliveira ${ }^{1}$ \\ Natália de Cássia Horta ${ }^{2}$ \\ Marina Celly Martins Ribeiro de Souza ${ }^{3}$ \\ Quesia Nayrane Ferreira ${ }^{4}$ \\ Michely Cristina Gonçalves Silva ${ }^{5}$
}

\begin{abstract}
RESUMO
Este artigo tem como objetivo analisar as percepções dos profissionais sobre as práticas por eles realizadas para a promoção da saúde do idoso institucionalizado. Trata-se de pesquisa descritivo-exploratória, de natureza quanti-qualitativa cujos dados foram coletados por meio de questionário aplicado em 156 Instituições de Longa Permanência de Idosos (ILPI) da Região Metropolitana de Belo Horizonte e dez grupos focais com a participação de 62 gestores e profissionais de 48 serviços. Realizou-se estatística descritiva dos dados dos questionários e análise de conteúdo proposta por Bardin para os grupos focais. Deste material emergiu a categoria: "Percepção da Promoção da Saúde no discurso dos participantes". Os achados negam o pressuposto inicial de que as ILPI têm ofertado cuidados mínimos, majoritariamente assistenciais, para essa população, pois se verificou uma variedade de ações ofertadas pelas instituições, além de eventos
\end{abstract}

\footnotetext{
Artigo recebido em 21 de outubro de 2019 e aprovado em 02 de março de 2020

${ }^{1}$ Mestrado em Saúde Pública e Doutorado em Ciências da Saúde pela Universidade Federal de Minas Gerais (UFMG). Nutricionista da Secretaria Municipal de Saúde - BH, professora do Curso de Nutrição da Pontifícia Universidade Católica de Minas Gerais (PUCMINAS), coordenadora da clínica de Nutrição da PUCMINAS, Brasil E-mail: tatianarangel@ pucminas.br.

2 Doutorado, Mestrado em Enfermagem pela Universidade Federal de Minas Gerais (UFMG). Coordenadora da Pesquisa e Líder do Grupo de Pesquisa PHASE no CNPQ, Professora Adjunta IV da Pontifícia Universidade Católica de Minas Gerais, lecionando nos Cursos de Enfermagem e de Medicina, Coordenadora do Curso de Especialização em Gerontologia da PUC Minas. Brasil. E-mail: nataliahorta@pucminas.br.

${ }^{3}$ Doutorado e Mestrado em Enfermagem pela Escola de Enfermagem da Universidade Federal de Minas Gerais (UFMG) . Associate Professor - Department of Public Health, The College of New Jersey, USA. E-mail: marinacelly.souza@gmail.com

${ }^{4}$ Mestranda em Enfermagem Pela Universidade Federal de Minas Gerais (UFMG). Enfermeira pela Pontifícia Universidade Católica de Minas Gerais (PUC Minas). Pesquisadora do Grupo de Pesquisa PHASE, Brasil. E-mail: quesiaferreira20@gmail.com

${ }^{5}$ Mestranda em Nutrição e Saúde pela Universidade Federal de Minas Gerais(UFMG), na área de concentração Saúde Pública. Membro do Grupo de Estudos, Pesquisas e Práticas em Ambiente Alimentar e Saúde (GEPPAAS) - UFMG, Graduação em Nutrição pela Pontifícia Universidade Católica de Minas Gerais (PUC Minas). Pesquisadora do Grupo de Pesquisa PHASE, Brasil. E-mail: michelygsilva@gmail.com
} 
Tatiana Resende Prado Rangel Oliveira, Natália de Cássia Horta, Marina Celly Martins Ribeiro de Souza, Quesia Nayrane Ferreira e Michely Cristina Gonçalves Silva

externos propostos pelos próprios idosos residentes. Não foi evidenciada diferença entre instituições privadas ou filantrópicas quanto à oferta de ações de promoção da saúde. Os resultados demonstraram que a gestão, a qualificação profissional, o trabalho em equipe multidisciplinar e a atenção à família têm um papel fundamental para a Promoção da Saúde do idoso institucionalizado. Adicionalmente, muitos participantes percebem a promoção da saúde ainda relacionada ao quantitativo de profissionais, recursos físicos e atividades oferecidas, mas alguns participantes já apontam para o reconhecimento da necessidade de se preservar e estimular a autonomia dos idosos como premissa básica para promover saúde.

Palavras-chave: Promoção da Saúde; Envelhecimento; Instituição de Longa Permanência para Idosos; Qualidade de vida.

\begin{abstract}
This paper aims to analyze the healthcare professionals' perceptions on the practices implemented to provide health promotion to institutionalized older adults. This is a mixed method, descriptive-exploratory study, whose data was collected through a questionnaire applied to 156 Long-Term Care Facilities (LTCF) in the Metropolitan Area of Belo Horizonte and ten focus groups with 62 managers and healthcare professionals from 48 institutions. Descriptive statistics and content analysis proposed by Bardin for the focus groups were performed. From the analysis emerged the category: "Perception of Health Promotion in the discourse of the participants". The findings deny the initial assumption that LTCF's have offered minimal basic care for this population, since a variety of actions were offered by the LTCF, in addition to external events proposed by the older adults themselves. There was no evidence of a difference between private and philanthropic facilities regarding the availability of health promotion actions. The results showed that management, professional qualification, multidisciplinary teamwork and family care have a fundamental role for the Health Promotion of the institutionalized older adults. Additionally, many participants perceive health promotion still related to the size of the staff, physical resources and activities offered, but some participants already pointed to the recognition of the need to preserve and stimulate the autonomy of the older adults as a basic premise to promote health.
\end{abstract}

Keywords: Health Promotion; Aging; Homes for the Aged; Quality of life.

\title{
INTRODUÇÃO
}

A promoção da saúde (PS) é um conjunto de estratégias para construção de projetos terapêuticos, no âmbito individual e coletivo, que respeite as especificidades e as potencialidades dos envolvidos, na tentativa de garantir a melhoria da qualidade de vida (QV). Caracteriza-se pela articulação intra e inter setorial, e pelo cuidado Rede com ampla participação e controle social (Brasil, 2015) com vistas à diminuição das vulnerabilidades (Malta et al, 2016). No contexto brasileiro, apesar da existência da 
política nacional de promoção da saúde, pode-se constatar que a simples edição de marcos legais não é condição suficiente para a efetivação de ações, sendo necessária a incorporação de instrumentos de monitoramento e avaliação específicos para esta política (Dias et al, 2018).

A promoção da saúde tem íntima relação com a qualidade de vida de um indivíduo ou comunidade, na medida em que os modos de vida, atrelados à percepção dos sujeitos sobre o bem-estar, a saúde, a felicidade, permitem a garantia das necessidades básicas e instrumentais e estilos de vida diferenciados.

Neste estudo adotamos o conceito de QV do World Health Organization Quality of Life Group (WHOQOL) que a define como "a percepção que o indivíduo tem de sua posição na vida, no contexto da cultura e no sistema de valores em que vive, e em relação aos seus objetivos, expectativas, padrões e preocupações" (Lima, et al, 2016; WHOQOL, 1994). O conceito de qualidade de vida compreende assim à multidisciplinaridade do conhecimento por englobar diversas formas de ciência e o conhecimento popular, além dos conceitos que permeiam a vida das pessoas como um todo. Envolve inúmeros elementos do cotidiano do ser humano, desde a percepção e a expectativa subjetiva sobre a vida até questões como o enfrentamento de doenças e enfermidades (Oliveira et al, 2017).

Destaca-se que no processo de envelhecimento, a QV está ligada à satisfação que o idoso sente no meio em que vive, ou seja, um constructo social e polissêmico, marcado pelo contexto, experiências e valores e, sobretudo, à sua autonomia (Arantes, 2016; Santos et al, 2016). Considera-se que as estratégias de PS são marcos fundamentais para a qualidade de vida em um país como o Brasil, que envelhece de forma mais acelerada, constituindo um dos maiores desafios da saúde pública atual (Miranda et al, 2016). Este contexto, associado aos modos de vida contemporâneos nos quais há mudanças nos arranjos e nas dinâmicas familiares, resultaram, nos últimos anos, em um aumento considerável da demanda por Instituições de Longa Permanência para Idosos (ILPI).

A atenção ao idoso institucionalizado tem características especiais e requer habilidades e competências específicas dos profissionais, como capacidade de avaliação multidimensional, de escuta e negociação de forma a preservar sua autonomia. A manutenção da independência física também é um fator importante para a promoção de 
Tatiana Resende Prado Rangel Oliveira, Natália de Cássia Horta, Marina Celly Martins Ribeiro de Souza, Quesia Nayrane Ferreira e Michely Cristina Gonçalves Silva

uma vida saudável, juntamente com a maior oferta de atividades que promovam prazer ao idoso (Santos et al, 2016).

Nesse estudo partiu-se do pressuposto de que as ILPI têm ofertado os cuidados mínimos, majoritariamente assistenciais, como abrigo e alimentação, voltados a essa população sem, no entanto, privilegiar a promoção da saúde. Assim, enquadrando-os em um nível de dependência de cuidados e de autonomia limitada que não os empodera para a manutenção de sua qualidade de vida e promoção da saúde.

Desta forma, este artigo, teve como objetivo analisar as percepções de profissionais e gestores sobre as práticas de promoção da saúde do idoso, desenvolvidas em Instituições de Longa Permanência para Idosos.

\section{METODOLOGIA}

Os resultados apresentados fazem parte da Pesquisa intitulada "Qualidade de Vida do idoso Institucionalizado: aspectos da promoção da saúde". Trata-se de uma pesquisa descritivo-exploratória de abordagem quanti-qualitativa, tendo como cenário os 34 municípios da Região Metropolitana de Belo Horizonte (RMBH), em Minas Gerais. Inicialmente foi realizado um levantamento das ILPI existentes e, posteriormente, aplicou-se questionário por meio de contato telefônico e visita in loco para conhecimento do perfil das 156 ILPI, identificando características básicas como o número de residentes, atividades ofertadas, dentre outros. Para análise destes dados utilizou-se a estatística descritiva, sendo os mesmos apresentados em termos de distribuição de frequência e gráfico.

Em seguida foram realizados grupos focais, como possibilidade de investigação que permite interação e geração de conhecimento a partir da discussão de temáticas específicas (Gatti, 2015). Foram realizados 10 grupos focais de fevereiro a junho de 2017 utilizando-se da seguinte questão norteadora: "O que vocês pensam sobre a promoção da saúde do idoso institucionalizado?" Todas as 156 instituições participantes da pesquisa foram convidadas para esta etapa com presença de 62 representantes de 48 ILPI (32 de natureza filantrópica e 16 instituições privadas).

Este estudo foi aprovado pelo Comitê de Ética em Pesquisa e os dados foram coletados após a assinatura do Termo de Consentimento Livre e Esclarecido (TCLE) por todos os participantes. 
O material empírico foi analisado segundo as etapas da Análise de Conteúdo proposta por Bardin (2016) na modalidade de análise temática. A primeira etapa consistiu na organização do material empírico com transcrição dos discursos obtidos durante os grupos focais. Nesse momento os grupos foram codificados de forma que todos fossem nomeados com a inicial "G" de grupo seguido pela inicial dos participantes como: G gestores, P profissionais e RT Referência Técnica. Os outros sete grupos foram numerados de 1 a 7. Desta forma, temos os seguintes códigos: GG, GP, GRT, G1, G2, G3, G4, G5, G6, G7. Para identificar as falas dos participantes estes foram numerados e codificados com a letra $\mathrm{P}$.

A análise iniciou-se por meio de leituras exaustivas dos discursos para estabelecimento das ideias centrais, seguida por leitura vertical, atravessando as respostas de cada participante e, horizontal, confrontando os diferentes participantes por idéias centrais, dando origem aos temas, com agrupamento daqueles recorrentes, resultando na categoria empírica.

Adotou-se a Hermenêutica-Dialética como referencial de análise buscando apreender a prática social dos indivíduos em seu movimento de consensos e contradições, considerando a realidade vivida e condicionados à historicidade, tendo como ponto de partida a manutenção e a extensão da intersubjetividade de uma intenção possível como núcleo orientador da ação (Minayo, 2014).

\section{RESULTADOS E DISCUSSÃO}

\subsection{Percepções da Promoção da Saúde no discurso dos participantes}

Dentre as 156 ILPI da Região Metropolitana de Belo Horizonte (RMBH) cenários deste estudo, 96 (62\%) são privadas e 60 (38\%) filantrópicas, com maior concentração em Belo Horizonte, capital do Estado, com 106 instituições, sendo 79 privadas e 27 filantrópicas (Lacerda et al, 2017).

Em relação à composição do quadro de profissionais atuantes nestas instituições, destacam-se os profissionais da saúde, sendo que a maior parte conta com profissionais da enfermagem, nutrição, fisioterapia e medicina. Além disso, todas as instituições possuem outras conformações de equipes compostas em sua maioria por cuidadores de idosos, sendo este o maior quantitativo de profissionais. Ainda pode-se dizer que grande 
Tatiana Resende Prado Rangel Oliveira, Natália de Cássia Horta, Marina Celly Martins Ribeiro de Souza, Quesia Nayrane Ferreira e Michely Cristina Gonçalves Silva

parte das ILPI filantrópicas possui assistente social e psicólogo devido à exigência do convênio firmado entre os municípios e as ILPIs (Lacerda et al, 2017). Em estudo realizado por Camarano e colaboradores (2010) as ações de assistência à saúde também eram as principais oferecidas pelas instituições, sendo que $66,1 \%$ ofereciam serviços médicos e $56 \%$ serviços de fisioterapia.

As ILPI, independente da natureza, privada ou filantrópica, ofertam atividades similares, com destaque para os cultos ecumênicos, oficinas de culinária, festas de confraternização e atividades físicas. Estas atividades são desenvolvidas pela equipe de profissionais das instituições, ou na ausência destes, por meio de voluntários sendo o voluntariado mais frequente nas ILPI filantrópicas. O gráfico abaixo apresenta o

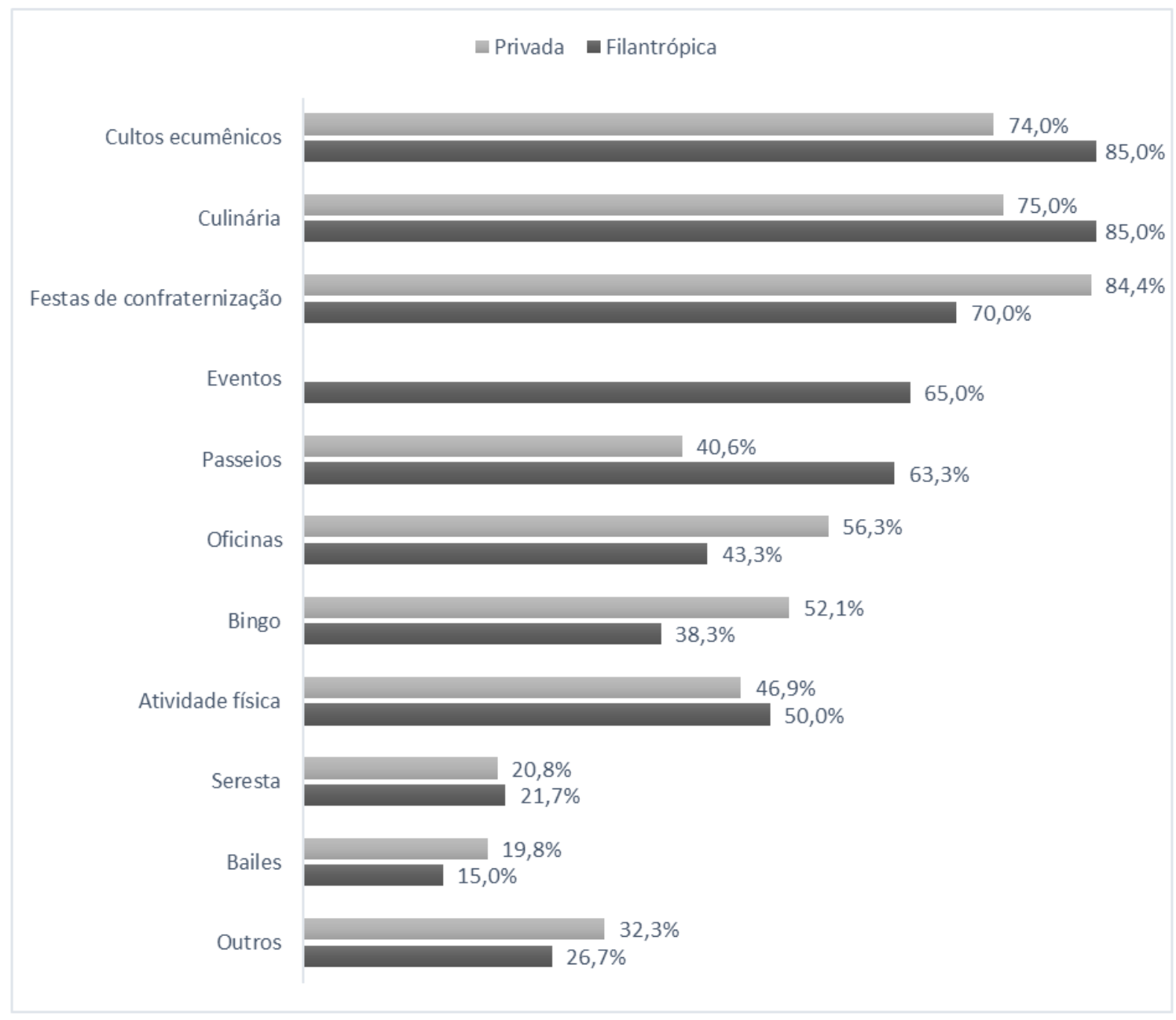

percentual destas atividades de acordo com a natureza das instituições:

Gráfico 1. Proporção de atividades coletivas em ILPI segundo natureza. Região Metropolitana de Belo Horizonte, Minas Gerais, 2016.

Fonte: Dados da pesquisa, 2018 
Alguns espaços de socialização e lazer para os idosos estão mais presentes nas ILPI privadas em relação às filantrópicas: sala de jogos, 13,5\% nas privadas e $10 \%$ nas filantrópicas; biblioteca, $11,5 \%$ nas privadas e 6,7\% nas filantrópicas; espaço de meditação e relaxamento, 7,3\% nas privadas e 3,3\% nas filantrópicas; academia 4,2\% nas privadas e 3,3\% nas filantrópicas; e sala de informática, 3,1\% nas privadas e 1,7\% nas filantrópicas. Infere-se que a menor disponibilidade destes espaços nas ILPI filantrópicas não pareceu ser um empecilho para a realização das atividades de promoção da saúde, sendo mencionadas pelos participantes dos grupos focais as estratégias de adequação dos espaços existentes para as atividades propostas, que podem ocorrer, por exemplo, no refeitório ou na sala de estar.

Os grupos focais produziram extensos relatos sobre promoção da saúde e a partir dos conceitos expressos foi possível elaborar o diagrama abaixo:

Figura 1: Diagrama sobre a promoção da saúde em ILPI

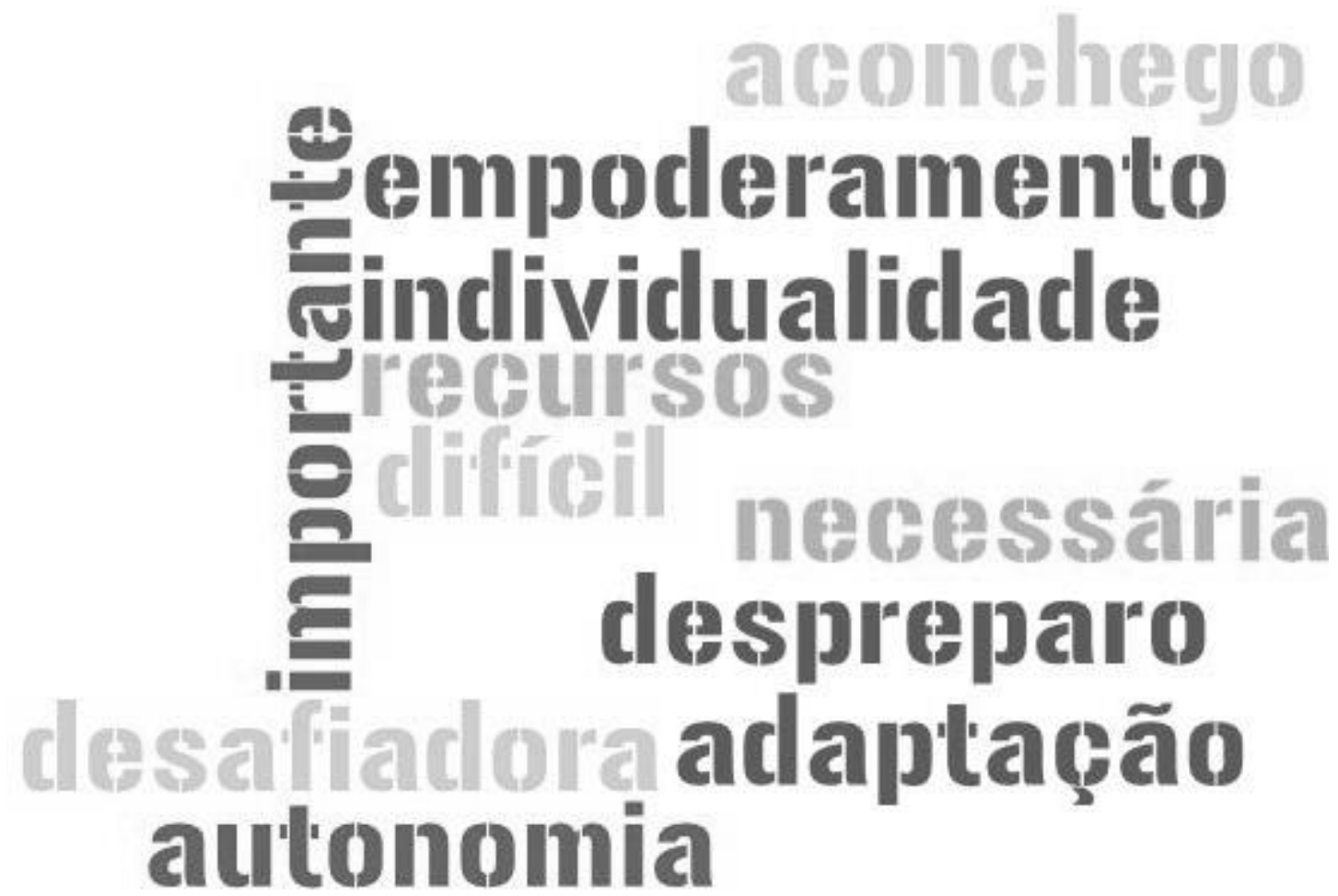

Fonte: Dados da pesquisa, 2018

Para os participantes dos grupos focais, as atividades socializantes e as oficinas terapêuticas promovem espaços para interação entre os residentes e destes com os facilitadores da atividade, formação de vínculos, elevação da auto estima, podendo 
Tatiana Resende Prado Rangel Oliveira, Natália de Cássia Horta, Marina Celly Martins Ribeiro de Souza, Quesia Nayrane Ferreira e Michely Cristina Gonçalves Silva

contribuir para a promoção da saúde. No entanto, estas atividades ofertadas devem considerar a subjetividade, o desejo e a autonomia do idoso, não sendo executadas de modo inflexível e imposto, perdendo assim a conotação de promoção da saúde:

A gente tenta também adaptar esse ambiente, pra poder ficar o mais confortável pra eles né, tentar deixar elas também fazerem o que elas têm vontade, umas gosta de costurar, sempre incentiva cada uma fazer o que realmente gosta, tentando criar aquele ambiente familiar assim pra elas, é, elas se sente aconchegante, elas se sente bem ali dentro... então essa promoção é fundamental né para fazer a qualidade de vida do idoso... cada vez mais independente a gente tem que tentar assim promover isso para manter a funcionalidade dele né, tentar melhorar a sua qualidade de vida $(G 2, P 2)$.

É importante ressaltar que as práticas citadas nos grupos como promotoras da saúde foram principalmente aquelas coletivas, apesar dos profissionais reconhecerem que é preciso preservar a individualidade dos idosos. Alguns profissionais ressaltaram a importância dos idosos na proposição das atividades e no cuidado que se deve ter com o excesso de ações. Citaram ainda a necessidade de se resgatar atividades praticadas antes da institucionalização como: costurar, cozinhar, fazer compras, ler e escrever textos. A qualificação e a visão mais humanizada dos profissionais mostram-se assim como fatores determinantes da PS:

Nossa! Isso vai ser legal para o idoso. Eu vou fazer". Mas é importante você ouvir dele o que é importante pra ele. Quando você trabalha com a coletividade, você não pode esquecer do individual. Então é, você dar empoderamento pro idoso, ele ser individual e viver no coletivo. (G1)

[...] nós fizemos um livro e eles trabalharam durante um ano com um tema que eles escolheram por exemplo água, e aí no final depois que eles escolheram quais as coisas que eles queriam colocar no livro a gente levou um fotógrafo para fotografar os próprios idosos, eles escolheram o lugar pra fotografar quem que iria ser por exemplo molhando o jardim quem que tava, quem que ia fazer o perfil do contorno, a música quem que iria sentar no piano e aí a gente montou um laboratório dentro da ILPI pra revelar as fotos. Eles participaram e as cores tinham que ser limitadas por causa de dinheiro e então nós levávamos as cores pra eles escolherem, a dedicatória, tudo que ia ser escrito quem iria participar e depois nós fizemos uma tarde 
de autógrafos chamamos a família e tudo, mas assim pra chegar nesse resultado acho que foi mais de um ano porque tudo também, é tudo no tempo deles. (G3 P1)

A preocupação dos participantes em ofertar ações e cuidados que visem uma melhor qualidade de vida aos idosos aponta para uma institucionalização diferente do paradigma reconhecido socialmente: abrigamento e alimentação resultando em isolamento familiar, social e comunitário. Deste modo, a concepção sobre promoção da saúde mostrou-se abrangente, com enfoque na qualidade de vida, manifestada em ações e vivências coletivas norteadas pelo respeito à individualidade, à religiosidade e à manutenção da autonomia dos idosos institucionalizados.

É, a comunidade também é bem participativa, sabe?! De jovens, é igual eu falo são várias pessoas. Nós somos ecumênicos na verdade. Então todo final de semana tem o pessoal da pastoral, tem o pessoal do evangélico, tem kardecista. Assim, eu acho que Deus né, sempre! Então assim, eles gostam, eles comungam, o padre uma vez por ano vai, faz a comunhão, escuta quem quer falar (...) (G1/ P2)

[...] É, tem uma idosa lá que uma vez por mês ela, ela fica mais dentro do quarto, ela lava as roupas dela, ela que faz tudo, ela não gosta que ninguém nem lave, ela que lava e pendura. Aí ela uma vez por mês gosta de ir no supermercado, ela faz a comprinha dela, então sempre eи ou a assistente social ou a psicóloga acompanha ela no supermercado, aí ela compra tudo que ela gosta. Todo mês tem que agendar um dia pra ela ir no supermercado. (GF1 P3):

No entanto, Camarano e Barbosa (2016) sugerem que existe uma "evolução para a dependência dentro das ILPI", os idosos entram com certa autonomia e com o tempo vão perdendo-a. Isto pode estar associado, dentre outros motivos, ao contexto histórico do surgimento dessas instituições, cercadas por caridade, podendo induzir a ideia de que o profissional está num lugar de quem detém poder frente ao idoso em posição de dependência (Cherix; Kovács, 2012).

Questões administrativas como a gestão, a qualificação e compromisso dos profissionais e o trabalho em equipe também foram reveladas como aquelas que interferem diretamente no cuidado e consequentemente na PS. Segundo Roquete, 
Tatiana Resende Prado Rangel Oliveira, Natália de Cássia Horta, Marina Celly Martins Ribeiro de Souza, Quesia Nayrane Ferreira e Michely Cristina Gonçalves Silva

Batista e Arantes (2017), a equipe multidisciplinar é fundamental no cuidado ao idoso em especial o cuidado a idosos institucionalizado visando o cuidado integral. Os autores adicionam que as instituições esbarram muitas das vezes na falta de recursos que impacta na contratação da equipe e na qualificação da mesma.

A visão ampla do gestor mostrou-se como um diferencial na gestão do cuidado, uma vez que este exerce um papel de extrema importância para potencializar as ações com foco na promoção da saúde.

Eu acho que a promoção da saúde também está vinculada diretamente ao responsável da instituição, [...]. A sensibilidade dele vai promover sim ou não, contribuirá sim ou não (G1P3).

O desafio para a PS é também do próprio profissional. Os participantes do grupo focal compreendem a sua função além dos cuidados com o corpo e sim com a história de vida construída dos sujeitos, as relações estabelecidas antes da institucionalização e o seu papel em garantir e trabalhar esses vínculos. Cabe aos profissionais proporcionar espaços para escuta, pois a família também se sente culpada pela institucionalização.

O cuidador apareceu como pouco contributivo e ora até mesmo como dificultador para o desenvolvimento de promoção de saúde na ILPI, seja pela sua não qualificação profissional, pela exigência de atribuições que não competem a sua formação ou porque ele contribui para a dependência do idoso. Alguns participantes mencionaram a rotatividade destes profissionais, devido à sobrecarga do trabalho.

[...] E é aí que vem o grande desafio, porque nem sempre a formação de cuidador é uma formação da forma que a gente queria, né. Então as vezes é um curso muito simples que eles fazem, então eu acho que é um grande desafio da promoção da saúde e do cuidado do idoso institucionalizado, é isso a capacitação desse cuidador (G3P4).

Com o aumento do número de ILPI a atuação dos cuidadores formais tem assumido cada vez mais um espaço importante, embora não haja muitos estudos sobre o assunto. A escassez de pesquisas específicas para o cuidador formal em ILPI atrelada a falta de regulamentação impactam na assistência prestada pelos cuidadores, predominando um cuidado próximo ao cuidado domiciliar (Barbosa et al., 2017). No entanto, a estratégia de educação continuada poderia minimizar este problema e trazer o 
cuidador como um agente de PS do idoso, principalmente por estarem mais próximos dos idosos, no cotidiano das instituições.

As ILPI, apesar de seu caráter de residência coletiva, apresentam demandas próprias de cuidados, pois abrigam residentes com características de saúde distintas, cedendo à demanda da assistência à saúde em função do grau de dependência dos idosos residentes (Salcher; Portella; Scortegagna, 2015). Esses cuidados vão desde os básicos, corriqueiros em um domicilio, àqueles mais complexos, como cuidados da enfermagem com trocas de curativos de lesões extensas, como também de outros profissionais como psicólogos, fisioterapeutas, assistentes sociais, terapeuta ocupacional. Para que haja uma interação adequada é importante uma liderança que motive o trabalho em equipe, principalmente no que diz respeito a PS.

Para os participantes, a falta de recursos financeiros, tanto para a contratação de profissionais, como para adequação de espaços adequados e materiais, é um fator que também dificulta as ações de PS:

Na verdade, lá nós não temos muitas opções é uma instituição filantrópica estamos passando por muitas dificuldades crise financeira mesmo tá, não temos profissional suficiente para atender a demanda da instituição nós não temos terapeuta ocupacional [...] a dificuldade que nós temos é a questão financeira principalmente nas instituições filantrópicas né, por que as particulares querendo ou não elas tem uma condição boa né, pra manter a casa e as filantrópicas não né. Eu acho que a dificuldade é essa (G5P1).

Para alguns participantes há diferença na oferta de atividades entre as instituições de acordo com sua natureza, sendo que na visão destes as instituições privadas têm mais recursos e por isso nelas existe mais promoção da saúde. Para muitos a promoção da saúde está pautada na quantidade de profissionais, recursos e atividades que são ofertadas. De certa forma se contradiziam, pois falavam das pequenas ações que tinham grande impacto para o idoso sendo estas realizadas em atividades do dia-a-dia em qualquer tipo de ILPI. Além disso, os resultados apresentados no gráfico 1 também não corroboram com esta percepção, diante da semelhança de atividades ofertadas independente da natureza das instituições. Isso porque muitas das vezes as filantrópicas contam com doações, bazares, parcerias e voluntariado (Roquete; Batista; Arantes, 2017). 
Tatiana Resende Prado Rangel Oliveira, Natália de Cássia Horta, Marina Celly Martins Ribeiro de Souza, Quesia Nayrane Ferreira e Michely Cristina Gonçalves Silva

A família é apontada nos discursos como ausente e indiferente ao cuidado prestado ao idoso:

[...] é eu acho que as vezes os familiares não tem a consciência que o trabalho ele é em conjunto, são as duas partes, né, que eu estou ali, que eu sou um prestador de serviço, eu estou oferecendo aquilo né, proporcionar ao idoso a melhor coisa, só que muitas vezes os familiares não tem essa visão, essa consciência vamos dizer assim, então as vezes o trabalho é feito unilateral, né, eu por ser uma casa privada, é as vezes o familiar acha que ele simplesmente por ele pagar uma mensalidade, é, ele ta abdicando de todo tipo de cuidado que ele teria, né, e não é assim, acho que começa por ai, né, essa questão (G2P1).

As relações estabelecidas com a família têm grandes impactos na QV dos idosos uma vez que irão buscar conforto e bem-estar nas relações amorosas e sociais que estabelecem (Roquete; Batista; Arantes, 2017). Desta forma, a família pode representar aspectos positivos e negativos de acordo com sua participação na institucionalização dos idosos e com a história de vida construída. Cabe a instituição por parte dos profissionais buscarem a manutenção, a construção e recuperação de vínculos e a interação do familiar ou responsável no cuidado ao idoso também como forma de PS. Sendo assim, a família também precisa ser um foco de atenção da equipe multiprofissional, devido ao seu papel significativo no cuidado ao idoso, principalmente quando institucionalizado.

Por fim, vale ressaltar que para promover saúde ao idoso institucionalizado é importante incentivar a sua participação em diferentes atividades, mas ao mesmo tempo reconhecendo sua individualidade e história de vida. Segundo Lima e colaboradores (2016), a maior variedade de atividades físicas, mentais, recreativas, culturais e espirituais estimula a adesão às mesmas. Salienta-se ainda, segundo Souza; Silva; Barros (2019), para a necessidade de que os governos e gestores compreendam o valor da educação e da promoção de saúde para todas as idades, e a importância do combate às injustiças sociais, empoderando os idosos para que sejam mais participativos e com o poder que podem ter e que possivelmente não estão totalmente cientes, o cumprimento das políticas a eles destinadas.

Entretanto, o excesso de atividades, por si só, não caracteriza PS. Para que uma atividade seja promotora de saúde, deve almejar a melhoria na qualidade de vida com 
participação ativa do idoso no processo e este precisa, ainda, se sentir representado nas ações. As práticas propostas devem ser do desejo do idoso e não do desejo do profissional, somente, em implantar atividades na instituição.

Nessa pesquisa, a vivência com os grupos focais configurou-se também como espaço de intercâmbio e troca de experiências entre os participantes de diferentes ILPI, sendo ressaltado por eles a necessidades de outros momentos como esses.

\section{CONSIDERAÇÕES FINAIS}

Os resultados demonstraram diferentes desafios que impactam de forma direta e indireta na PS dos idosos institucionalizados. A gestão, a qualificação profissional, em especial do cuidador, o trabalho em equipe multidisciplinar e a atenção à família têm um papel fundamental para a PS do idoso institucionalizado.

Não foi revelada a existência de diferenças significativas entre a natureza da ILPI e as ações promotoras da saúde ofertadas, embora alguns participantes tenham relatos diferentes. Os resultados ainda negam o pressuposto do estudo, de que as ILPI têm ofertado cuidados mínimos, majoritariamente assistenciais, para essa população. Há oferta de diferentes ações que demonstram a preocupação das instituições em promover a saúde do idoso com foco na preservação da autonomia e história de vida construída.

\section{REFERÊNCIAS}

ARANTES, Rodrigo Caetano. Diretrizes para a gestão do envelhecimento ativo e com qualidade de vida para idosos brasileiros. In: Lina Faria, Calábria Luciana Karen, Alves Waneska Alexandra, organizadoras. Envelhecimento: um olhar interdisciplinar. São Paulo: Hucitec; 2016. p.188-214.

BARBOSA, Lara de Melo et al . Qualidade de vida relacionada à saúde dos cuidadores formais de idosos institucionalizados em Natal, Rio Grande do Norte. Revista Brasileira de Estudos de População, São Paulo, v. 34, n. 2, p. 391414, maio/ago. 2017 .

BARDIN, Laurence. Análise de conteúdo. Ed. rev. e ampl. Lisboa: Ed. 70, 2016. 279 p.

BRASIL. Ministério da Saúde. Secretaria de Vigilância em Saúde. Secretaria de Atenção à Saúde. Política Nacional de Promoção da Saúde: PNPS: revisão da Portaria MS/GM n 687, de 30 de março de 2006/ Ministério da Saúde, Secretaria de 
Tatiana Resende Prado Rangel Oliveira, Natália de Cássia Horta, Marina Celly Martins Ribeiro de Souza, Quesia Nayrane Ferreira e Michely Cristina Gonçalves Silva

Vigilância em Saúde, Secretaria de Atenção à Saúde. - Brasília: Ministério da Saúde, 2015.

CAMARANO, Ana Amélia.; BARBOSA, Pamela. Instituições de Longa Permanência para idosos no Brasil: do que se está falando? In: CAMARANO, Ana Amélia (Org.). Política Nacional do Idoso: velhas e novas questões. Rio de Janeiro: Ipea, 2016. p. 479-514.

CAMARANO Ana Amélia et al. As instituições de longa permanência para idosos no Brasil. In: Camarano AA. Cuidados de longa duração para a população idosa: um novo risco social a ser assumido? Rio de Janeiro: IPEA; 2010. p.187-212.

CHERIX, Kátia; KOVÁCS, Maria Julia. A questão da morte nas Instituições de Longa Permanência para Idosos. Revista Temática Kairós Gerontologia, São Paulo, v. 15, n. 4, p. 175-184, 2013.

DIAS, Maria Socorro de Araújo et al. Política Nacional de Promoção da Saúde: um estudo de avaliabilidade em uma região de saúde no Brasil. Ciência \& Saúde Coletiva, v. 23, n. 1, p.103-114, jan. 2018.

GATTI, Ana Lúcia et al. Pesquisa Qualitativa: Grupo Focal e Intervenções Psicológicas com Idosos. Psicologia: Ciência e Profissão, Brasília, v. 35, n. 1, p. 20-39, mar. 2015.

LACERDA, Tatiana Teixeira Barral de et al. Caracterização das Instituições de longa permanência para idosos da região metropolitana de Belo Horizonte. Revista Brasileira de Geriatria e Gerontologia, v. 20, n. 6, p.743-753, dez. 2017.

LIMA, Ana Priscila Marques et al. Qualidade de vida sob a óptica da pessoa idosa institucionalizada. Revista Brasileira de Promoção da Saúde, Fortaleza, v. 1, n. 26, p.14-19, 2016.

MALTA, Deborah Carvalho et al. Política Nacional de Promoção da Saúde (PNPS): capítulos de uma caminhada ainda em construção. Ciência \& Saúde Coletiva, v. 21, n. 6, p.1683-1694, jun. 2016.

MINAYO, MC. O desafio do conhecimento: pesquisa qualitativa em saúde. 14. ed. São Paulo: Hucitec, 2014.

MIRANDA, Gabriella Morais Duarte; MENDES, Antonio da Cruz Gouveia; SILVA, Ana Lucia Andrade da. Population aging in Brazil: current and future social challenges and consequences. Rev Bras Geriatr Gerontol. Rio de Janeiro, v. 19, n. 3, p. 507-519, 2016.

OLIVEIRA, Beatriz Campos de et al. Avaliação da qualidade de vida em idosos da comunidade. Revista Brasileira em Promoção da Saúde, v. 30, n. 3, p.1-10, set. 2017.

ROQUETE, Fátima Ferreira; BATISTA, Carolina Campos Ricci Frá; ARANTES, Rodrigo Caetano. Care and management demands of long-term care facilities for the elderly in Brazil: an integrative review (2004-2014). Revista Brasileira de Geriatria e Gerontologia, v. 20, n. 2, p.286-299, abr. 2017. 
SALCHER, Eduarda Brum G.; PORTELLA, Marilene R.; SCORTEGAGNA, Helenice de Moura. Cenários de instituições de longa permanência para idosos: retratos da realidade vivenciada por equipe multiprofissional. Revista Brasileira de Geriatria e Gerontologia, Rio de Janeiro, v. 18, n. 2, p, 259-272, 2015.

SANTOS, Rebeca Aranha Arrais e Silva et al. Atenção no cuidado ao Idoso: Infantilização e desrespeito à autonomia na assistência de enfermagem. Revista de Pesquisa em Saúde, v. 17, n. 3, p.179-183, set/dez. 2016.

SOUZA, Elza Maria de; SILVA, Daiane Pereira Pires; BARROS, Alexandre Soares de. Educação popular, promoção da saúde e envelhecimento ativo: Uma revisão bibliográfica integrativa. Ciência e Saúde coletiva, jul. 2019. [Periódico online]. Disponível em: <http://www.cienciaesaudecoletiva.com.br/artigos/educacao-popularpromocao-da-saude-e-envelhecimento-ativo-uma-revisao-bibliografica-

integrativa/ $17275 ? \mathrm{id}=17275 \& \mathrm{id}=17275 \& \mathrm{id}=17275$ > . Acesso em: 18 out. 2019.

THE WHOQOL GROUP. The development of the World Health Organization quality of life assessment instrument (the WHOQOL). In: Orley J, Kuyken W, editores. Quality of life assessment: international perspectives. Heidelberg: Springer Verlag; 1994. p. 41-60. 